\title{
Task force tackles rural health care inequity
}

- Cite as: CMAJ 2017 April 3;189:E514. doi: 10.1503/cmaj.1095407

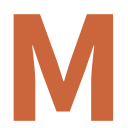

aking health care more equitable and accessible for the $18 \%$ of Canada's population living in rural communities, but served by only $8 \%$ of the country's physicians, is the driving force behind the report Rural Road Map for Action: Directions. The sixpage strategy, released by a joint task force of the College of Family Physicians of Canada (CFPC) and the Society of Rural Physicians of Canada (SRPC), puts forward 20 action items under four overarching directions.

The breadth of the recommendations, including ideas to support Canadian medical schools in developing physicians who are equipped to work in rural communities, is deliberate. "They are principles about what we think people should do," said Dr. Trina Larsen Soles, a cochair of the task force. "They are big broad actions. We didn't want to limit people."

One of the more controversial recommendations, and a particular favorite of cochair Dr. Ruth Wilson, is the establishment of a rural medicine service that would provide a skilled workforce of rural family physicians and generalist-specialists ready and able to work across provincial and territorial jurisdictions, enabled by the creation of a special national locum licence designation. The service could be used "to plug some of the holes that pop up suddenly in our rural communities," said Wilson, a professor of family medicine at Queen's University.

"This kind of service would appeal to doctors at the beginning of their careers and boomers at the end of their careers," she added.

Other action items include establishing formal and informal mentorships to support rural physicians, creating a Canadian rural health services research network and supporting extended training in rural communities to prepare medical students and residents.

"There is no magic bullet, but there is a whole suite of activities," said Wilson. "It starts with recruiting people from rural and aboriginal communities and integrating this reality into medical schools." three years ago doesn't wane. An implementation plan will be rolled out within the next two months and a follow-up report card will be issued within two years.

In the meantime, other ideas, such as the creation of a database so health care professionals and organizations across

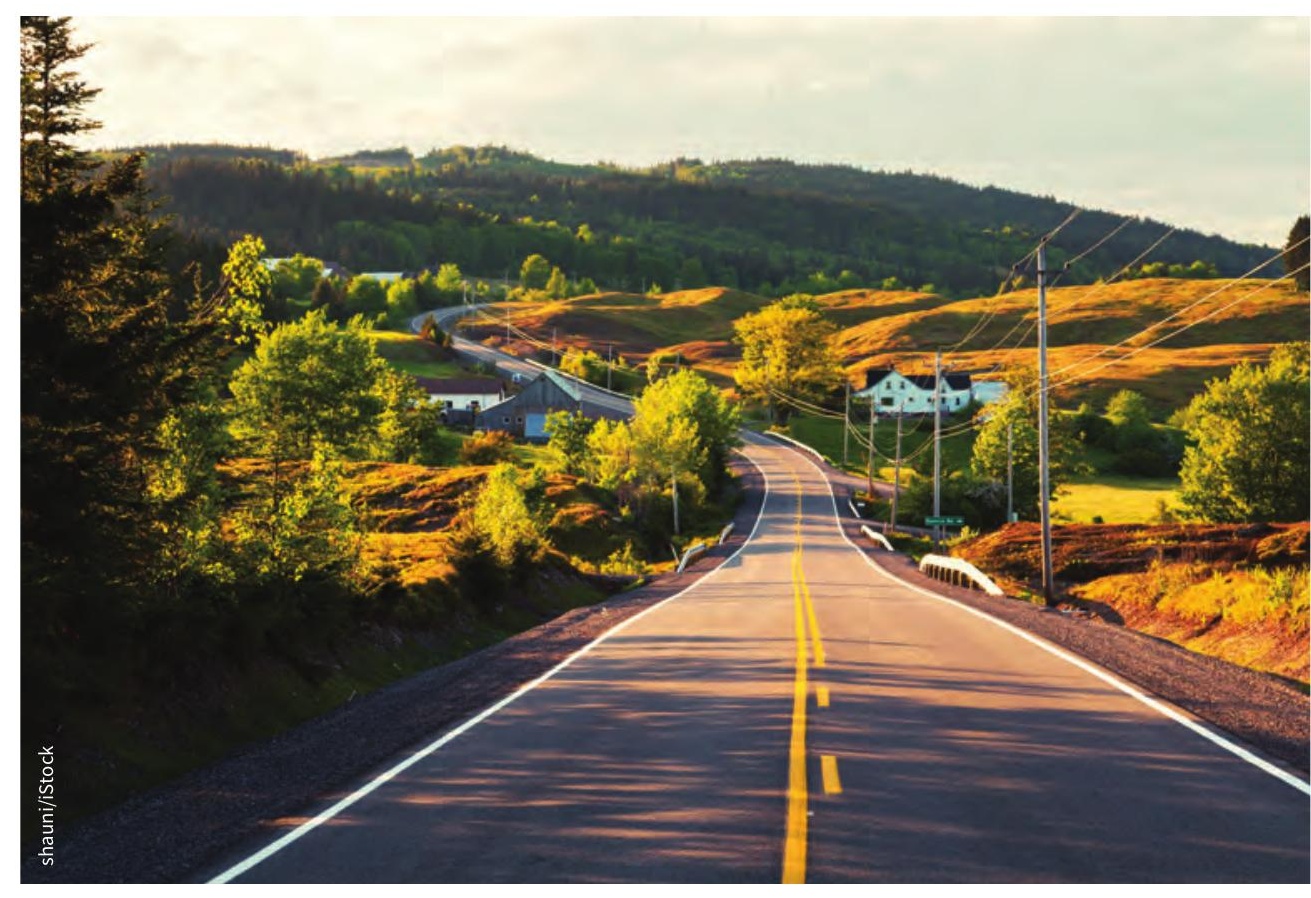

A physician task force has proposed a road map for improving health care equity and accessibility for Canada's underserved rural population.

Following a one-day national summit recently held in Ottawa, the work of the task force is officially over. Now the work to transform the group's wish list into reality has begun. "Whenever you do policy work, you often produce a really lovely reference document that just sits there," acknowledged Soles, the president-elect of Doctors of BC.

The task force cosponsors and other summit participants are working to ensure the momentum and awareness that has been built since the task force was created the country can see what is happening in other locations, are being explored. "There are so many initiatives going on. The problem is it's not well coordinated," said Soles.

In many cases, the ideas brought forward by the task force are not new, said Wilson, who has 11 years of practice experience in Northern and remote Canada. "It's a question of implementing them and being dogged in ensuring they happen."

donalee Moulton, Halifax, Nova Scotia 